Article

\title{
An Empirical Study of Carbon Emission Impact Factors Based on the Vector Autoregression Model
}

\author{
Wei Fan ${ }^{1}$, Xi Luo ${ }^{2}$, Jiabei Yu ${ }^{2}$ and Yiyang Dai ${ }^{2, *(D)}$ \\ 1 Bureau of Economic Information and Science and Technology of Daying, Suining 629300, China; \\ fanwei@swpu.edu.cn \\ 2 School of Chemical Engineering, Sichuan University, Chengdu 610065, China; luoxi@stu.scu.edu.cn (X.L.); \\ yujb_scu@163.com (J.Y.) \\ * Correspondence: daiyy@scu.edu.cn; Tel.: +86-180-1060-5143
}

check for updates

Citation: Fan, W.; Luo, X.; Yu, J.; Dai, Y. An Empirical Study of Carbon Emission Impact Factors Based on the Vector Autoregression Model. Energies 2021, 14, 7797. https:// doi.org/10.3390/en14227797

Received: 5 October 2021

Accepted: 16 November 2021

Published: 22 November 2021

Publisher's Note: MDPI stays neutral with regard to jurisdictional claims in published maps and institutional affiliations.

Copyright: (c) 2021 by the authors. Licensee MDPI, Basel, Switzerland. This article is an open access article distributed under the terms and conditions of the Creative Commons Attribution (CC BY) license (https:/ / creativecommons.org/licenses/by/ $4.0 /)$.

\begin{abstract}
It is important to effectively reduce carbon emissions and ensure the simultaneous adjustment of economic development and environmental protection. Therefore, we used Kaya identity to screen the factors influencing carbon emissions and conducted preliminary qualitative analyses, including grey relation analysis and linear regression analysis, on important variables to establish a vector autoregression (VAR) model based on their annual data to empirically analyze the influencing factors of carbon emissions. The results showed that economic growth effect, energy intensity effect and embodied carbon in foreign trade were the key factors affecting carbon emissions, among which the economic growth effect contributed the most. Accordingly, we propose countermeasures including technological innovation to reduce energy intensity, the development of new energy sources to improve energy structure, acceleration of industrial structure transfer, and optimization of trade structure.
\end{abstract}

Keywords: carbon emissions; VAR model; economic; energy; foreign trade

\section{Introduction}

The consumption of high-carbon energy, such as coal and oil, has led to a significant increase in greenhouse gas emissions, making global ecological protection a challenge [1]. Carbon emissions refer to the average greenhouse gas emissions generated during the production, transportation, use, and recycling of a product. Since the beginning of the 21st century, compared with the previous three decades, the global greenhouse gas emissions have increased, mainly due to the increased carbon dioxide emissions of China, India, and other emerging economies [2]. The International Energy Agency (IEA) reported that global energy-related carbon dioxide $\left(\mathrm{CO}_{2}\right)$ emissions plateaued in 2019 at $33 \mathrm{Gt}$ [3]. According to data from the United Nations Environment Programme (UNEP) [4,5], over the last decade, the top four emitters headed by China accounted for 55 percent of global Greenhouse Gas emissions. China contributed to more than a quarter of global greenhouse gas emissions, and has per capita emissions about $40 \%$ higher than the global average. Since 2006, China has exceeded the USA and become the world's largest emitter of carbon dioxide [6]. The huge amount of carbon emissions has already had a serious impact on our people's lives and even the global environment, so it is extremely urgent to reduce carbon emissions.

China is a big energy producer but also a big energy consumer. Based on data in the China Energy Statistical Yearbook [7], Figure 1 shows the growth trend of China's total energy consumption since 1980. Although China's total energy consumption is growing, its energy consumption structure is continuously optimized. During the period from 1990 to 2018, although the absolute value of using coal to generate electricity in China increased, its proportion declined [8]. The statistical bulletin of the people's Republic of China on national economic and social development in 2020 [9] shows that in 2020, China's energy consumption structure continued to be optimized, the proportion of coal consumption 
further dropped to less than $57 \%$, and the proportion of clean energy consumption such as natural gas, water, nuclear, wind, electricity, and so on in the total energy consumption increased to $24.4 \%$. Between one increase and one decrease, the carbon emission reduction effect is significant. As can be seen from Figure 2, since 1980, the proportion of fossil energy consumption in China has decreased year by year, and the energy consumption structure has been gradually optimized.

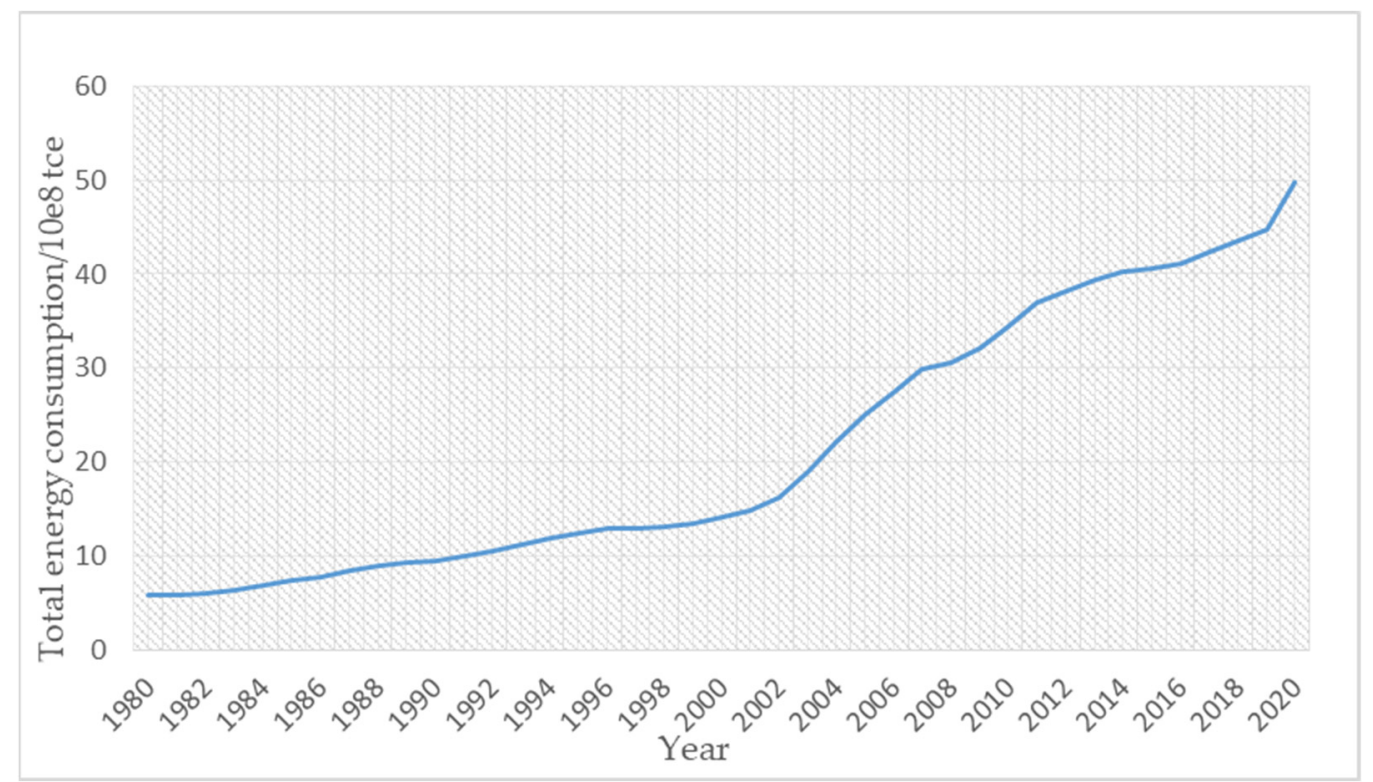

Figure 1. Trend chart of total energy consumption in China.

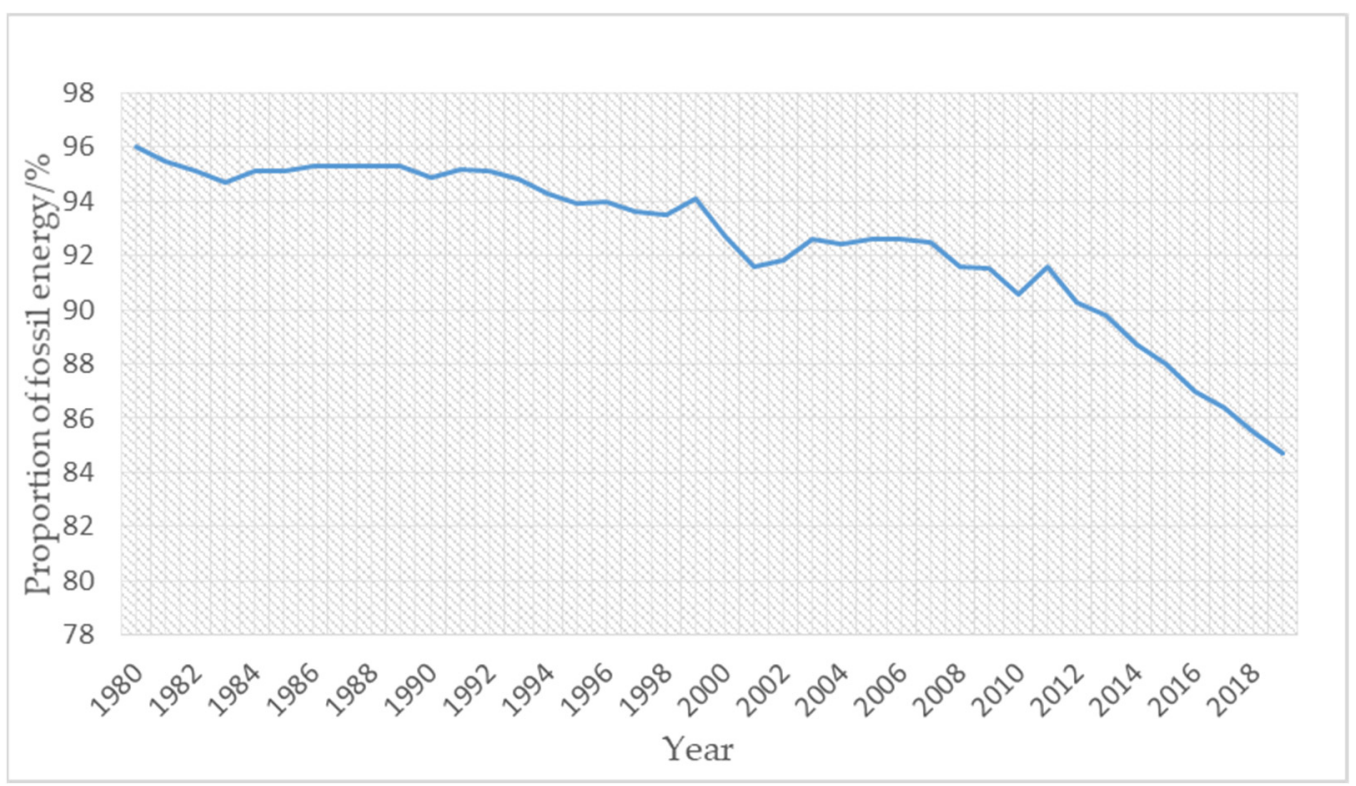

Figure 2. Trend chart of fossil energy consumption in China.

With the rapid economic growth, China's total primary energy consumption continues to increase. According to the data of the National Bureau of statistics [10], comparing the growth rate of total primary energy consumption with that of GDP, it can be seen that the growth rate of energy consumption in most years from 1978 to 2020 was lower than that of GDP, so China's energy intensity (energy consumption per unit GDP) showed a downward trend, as shown in Figure 3. 


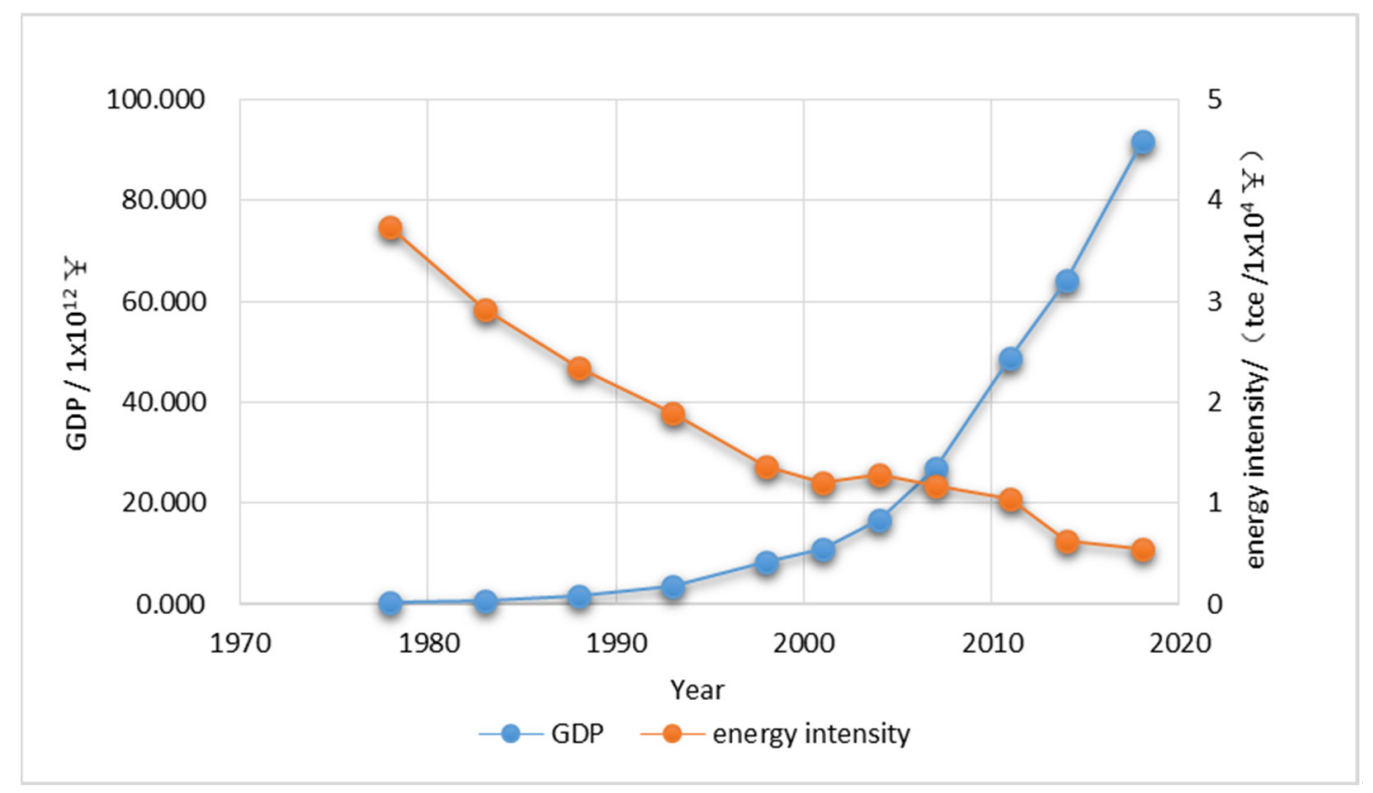

Figure 3. Trend chart of GDP and energy intensity in China.

According to the data of the China Energy Statistics Yearbook [7]. Figure 4 shows the change trend of China's total carbon emissions and carbon emission intensity from 1978 to 2020, from which it can be seen that China's total carbon emissions are increasing year by year, while its carbon emission intensity is decreasing year by year. Although China's total carbon emissions have shown a trend of increasing year over year, China's carbon intensity (carbon dioxide emissions per unit of GDP) has shown a downward trend with the improvement of energy efficiency and the development of new energy sources [11]. China's low-carbon transformation has achieved remarkable results, and with the adjustment and optimization of industrial structure and technological progress, carbon emission reduction methods tend to be diversified [12]. China aims to peak carbon dioxide emissions before 2030 and achieve carbon neutrality before 2060 [13]. Carbon neutrality is an unprecedented self-revolution in human history. Many factors need to be considered in the process of realizing carbon neutrality and the coordinated development of energy, the economy, and the environment [14]. Therefore, only by determining the key factors affecting carbon emissions can we formulate a more effective strategy to achieve coordinated development.

Traditional analysis methods are based on artificial qualitative knowledge, which ties the results of the analysis to the analyst. Therefore, personal qualitative analysis is limited. With the development of intelligent methods, their use to mine the internal relationships of data have become the mainstream [15]. The research on the factors affecting carbon emissions at home and abroad mainly includes the Laspeyres decomposition method, Arithmetic Mean Divisia Index (AMDI) method, and the Logarithmic Mean Divisia Index (LMDI) method [16]. Among these, Liu used the LMDI model to determine the differences of influencing factors of carbon emissions in central, eastern, and western China [17]. Zhang et al. (2021) first used an indicator decomposition based on the GDIM (Generalized Divisia Index Method) to analyse the influencing factors of carbon emissions in China's logistics industry, and used the multi-regional input-output model (MRIO) and Logarithmic Mean Divisia index approach to analyze the changes in China's carbon embodied in exports [18]. Sun et al. proposed an extended STIRPAT (stochastic impacts by regression on population, affluence, and technology) model to identify the main driving factors affecting $\mathrm{CO}_{2}$ emissions [19]. Piłatowska and Geise estimated the threshold vector autoregression (TVAR) model, and analysed the relationship between renewable and $\mathrm{CO}_{2}$ emissions and economic growth [20]. Then, based on the vector autoregression (VAR) model, they explored the impact of clean energy and non-renewable energy consumption on carbon emissions and economic growth [21]. The VAR model is one of the most basic models in 
multivariate time series analysis and one of the easiest models to analyze and predict multiple relevant economic indicators. Based on the advantages and disadvantages of qualitative methods and intelligent methods, this study used qualitative methods for preliminary analysis of the research content, and then used VAR models for quantitative analysis to achieve an in-depth investigation of carbon emission impact factors, relationships, and degrees, and to provide suggestions.

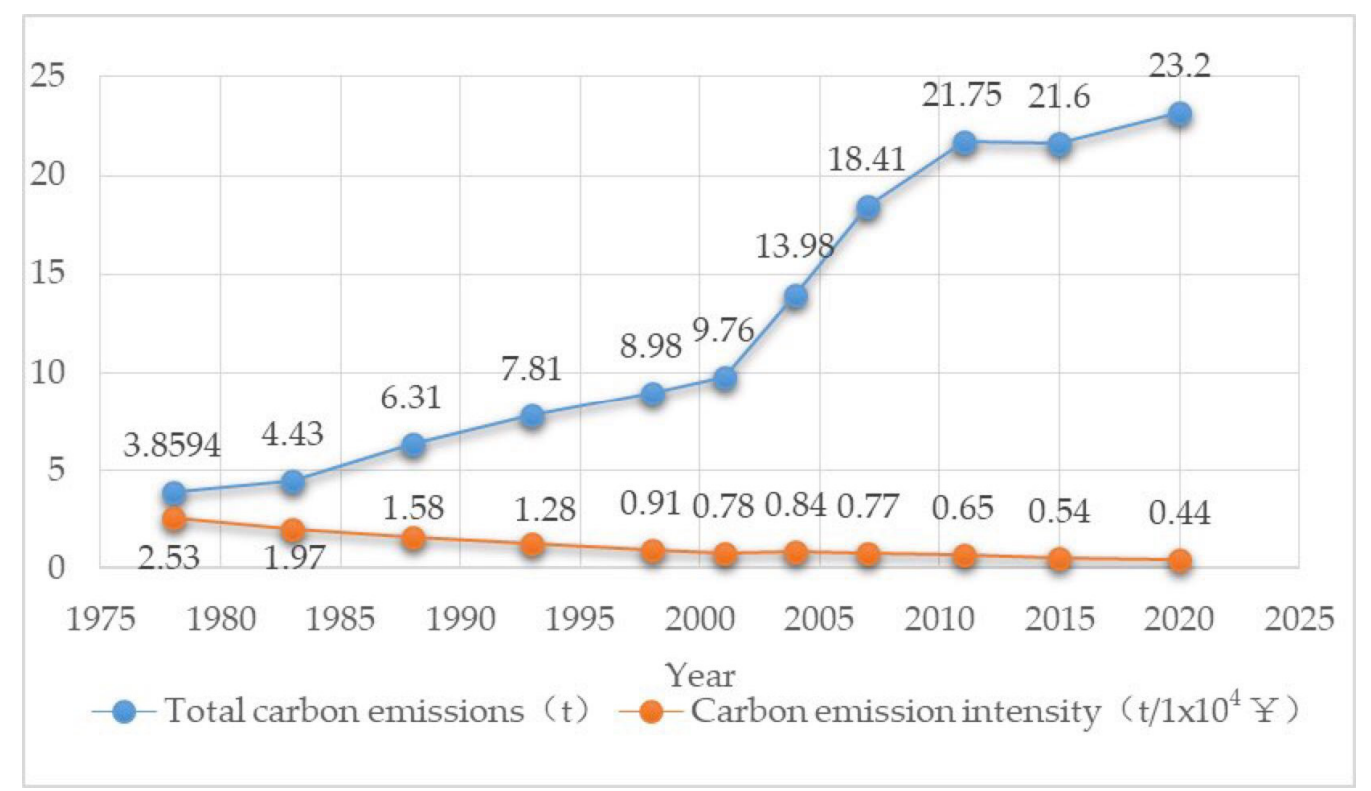

Figure 4. Trend of total carbon emissions and carbon intensity in China.

The rest of this paper is organized as follows: Section 2 focuses on the principles of the relevant methods applied in this paper; Section 3 introduces the designed analysis method; Section 4 presents the process and results of the example analysis of the method; Section 5 gives conclusions and recommendations.

\section{Methods}

The factors affecting carbon emissions are so diverse that an artificial list is inevitably time-consuming and incomplete. In this study, we first screened the main variables using the Kaya identity, and then explored them in depth qualitatively based on the results of two types of basic statistical methods: grey relation analysis and best subsets regression method. To reach more generalized conclusions, in the quantitative aspect, this article used the VAR model to carry out quantitative analysis. This section will introduce the mechanism models involved.

\subsection{Kaya Identity}

The Kaya identity is the current mainstream analysis method for analyzing the driving factors of carbon emissions. It plays an important role in explaining the causes of global historical emission changes. The Kaya identity links economic, policy, and demographic factors with the carbon dioxide emissions generated by human activities. It reflects the influence of energy and economic structures on emissions and can uncover the deep-seated factors leading to carbon emission changes. At the same time, the Kaya identity has good extensibility and can be further deconstructed according to the actual situation in the process of use. It has the advantages of a simple mathematical form, no residuals in decomposition, and strong explanatory power for the driving factors of carbon emission 
changes. Therefore, the Kaya identity is widely used in the carbon emissions decomposition problems. The following is its theoretical formula.

$$
C=\frac{C}{E} \times \frac{E}{G} \times \frac{G}{P} \times P
$$

where $C$ represents carbon dioxide emissions; $E$ represents total energy consumption; $G$ represents gross domestic product (GDP); C/E represents carbon emissions per unit of energy consumption, that is, energy structure carbon intensity; E/G represents energy consumption (l) per unit of GDP, that is, energy intensity; G/P represents GDP per capita; $P$ represents total domestic population.

\subsection{Grey Relation Analysis}

Grey relation analysis (GRA) is a method of multi-factor statistical analysis that measures the degree of relevance between factors based on the degree of similarity or dissimilarity in development trends between factors (grey relation). There are three forms of generalized grey relation analysis model, which are listed below.

Absolute gray relation analysis model: This analyzes the relationship between the absolute quantities of a series

$$
\varepsilon_{i j}=\frac{1+\left|s_{i}\right|+\left|s_{j}\right|}{1+\left|s_{i}\right|+\left|s_{j}\right|+\left|s_{i}-s_{j}\right|}
$$

Relative gray relation analysis model: This analyzes the relationship between the change rate of the series relative to the starting point

$$
\mathrm{r}_{\mathrm{ig}}=\frac{1+\left|\mathrm{s}_{\mathrm{i}}{ }^{\prime}\right|+\left|\mathrm{s}_{\mathrm{j}}{ }^{\prime}\right|}{1+\left|\mathrm{si}_{\mathrm{i}}\right|+\left|\mathrm{s}_{\mathrm{j}}{ }^{\prime}\right|+\left|\mathrm{s}_{\mathrm{i}}{ }^{\prime}-\mathrm{s}_{\mathrm{j}}{ }^{\prime}\right|}
$$

Integrated gray relation analysis model: This is obtained by combining the first two models, and it considers both the relationship between the absolute quantities of a series and the relationship between the change rate of the series relative to the starting point

$$
\rho_{\mathrm{ij}}=\theta \varepsilon_{\mathrm{ij}}+(1-\theta) \mathrm{r}_{\mathrm{ij}}
$$

where $s_{i}$ and $s_{j}$ represent the absolute sequence of the two factors, respectively; $s_{i}{ }^{\prime}$ and $s_{j}{ }^{\prime}$ represent the relative sequence of the two factors, respectively; $\theta$ is the synthesis coefficient, which can be adjusted appropriately according to the degree of emphasis on the two factors.

\subsection{Best Subsets Regression}

Best subsets regression is required when there is severe multicollinearity among the factors, which is an efficient way to confirm the target model with as few predictor variables as possible. Therefore, the method requires a multicollinearity diagnosis for all the factors first. Multicollinearity refers to the fact that the explanatory variables in the linear regression model have precise or highly correlated relationships, making the model estimates distorted or easily inaccurate. The principle of the best subsets regression is as follows.

Assuming a total of $\mathrm{k}$ variables, the variable dataset used in the original regression is as follows

$$
X=\left[x_{1}, x_{2}, \ldots, x_{k-1}, x_{k}\right]
$$


Subsequently, $x_{i}$ is used to represent the dataset corresponding to the $\mathrm{i}$-th variable, and $\mathrm{i} \in(1, \mathrm{k})$. According to the subset, there are $2 \mathrm{k}$ in total, and they are named M0, M1, M2, and M3. A linear regression is performed as shown in Equation (6)

$$
\hat{y}_{\mathrm{m}}=\sum_{\mathrm{i}=0}^{\mathrm{m}} \mathrm{b}_{\mathrm{i}} \mathrm{x}_{\mathrm{i}}
$$

Then, the $\mathrm{R}^{2}$ error calculation method is used to calculate each subset, and the principle is as follows

$$
\mathrm{R}_{\mathrm{m}}^{2}=1-\frac{\sum\left(\mathrm{y}_{\mathrm{j}}-\hat{\mathrm{y}}_{\mathrm{mj}}\right)^{2}}{\sum\left(\mathrm{y}_{\mathrm{j}}-\overline{\mathrm{y}}\right)^{2}}
$$

Among them, $y_{j}$ is the response value of the $j$-th sample point; $\hat{y}_{m j}$ is the predicted value of the equation fitted by the subset $m$ at the $j$-th sample point; $\bar{y}$ is the average of the historical response values.

Then, the optimal subset is

$$
\mathrm{M}^{*}=\operatorname{argmin}\left(\mathrm{R}_{\mathrm{m}}^{2}\right)
$$

\subsection{VAR Model}

The VAR model examines multivariate time series variables and builds relationships among variables based on the statistical nature of the data using an unstructured approach. It constructs the model by treating each endogenous variable in the system as a function of the lagged values of all endogenous variables to estimate the dynamic relationships of the joint endogenous variables without any prior constraint. Considering that the factors affecting carbon emissions also influence each other, the VAR model without prior constraints was chosen in this study

$$
\mathrm{Y}_{\mathrm{t}}=\mathrm{A}_{1} \mathrm{Y}_{\mathrm{t}-1}+\mathrm{A}_{2} \mathrm{Y}_{\mathrm{t}-1}+\cdots+\mathrm{A}_{\mathrm{p}} \mathrm{Y}_{\mathrm{t}-\mathrm{p}}+\mu_{\mathrm{t}}
$$

where $Y_{t}$ is the $n$-dimensional endogenous variable in period $t$; at any period $t$, the observed vector is $\mathrm{y}_{\mathrm{t}}=\left(\mathrm{y}_{1 \mathrm{t}}, \mathrm{y}_{2 \mathrm{t}}, \ldots, \mathrm{y}_{\mathrm{Nt}}\right)^{\mathrm{T}}$. Moreover, the number of variables in the observed vector is $\mathrm{N}, \mathrm{A}_{\mathrm{p}}$ is the corresponding coefficient matrix, $\mathrm{p}$ is the lag order of the $\mathrm{n}$-dimensional endogenous variable, and $\mu_{\mathrm{t}}$ is the disturbance term.

The complete VAR model validation includes units such as data stationarity test, VAR model establishment and lag order determination, variable exogeneity test, model stability test, cointegration test, variable causality test, variable impulse response, and impact level analysis.

\section{Determination of Carbon Emission Impact Factors}

\subsection{Determination of Decisive Factors Based on the Kaya Identity and Grey Relation Analysis}

As the driving force for exploration is the driving force for exploring the amount of change, based on Equation (1), after taking the amount of change and performing a logarithmic transformation, the additive function of $\mathrm{CO}_{2}$ emissions is obtained, as shown below

$$
\Delta \mathrm{C}=\mathrm{C}_{\mathrm{t}}-\mathrm{C}_{0}=\frac{\mathrm{C}_{\mathrm{t}}-\mathrm{C}_{0}}{\ln \mathrm{C}_{\mathrm{t}}-\ln \mathrm{C}_{0}} \times\left(\ln \mathrm{C}_{\mathrm{t}}-\ln \mathrm{C}_{0}\right)=\Delta \mathrm{E}+\Delta \mathrm{I}+\Delta \mathrm{B}+\Delta \mathrm{P}
$$

where $\Delta \mathrm{C}$ represents the difference between the $\mathrm{CO}_{2}$ emissions in year $\mathrm{t}$ and the carbon emissions $\mathrm{C}_{0}$ in the base year, $\Delta \mathrm{E}$ represents the energy structure carbon intensity effect, $\Delta \mathrm{I}$ measures the energy intensity effect, $\Delta \mathrm{B}$ measures the economic growth effect, and $\Delta \mathrm{P}$ measures the population effect. The above equation illustrates that the change in carbon dioxide emissions is determined by the four main indicators: the energy structure carbon 
intensity effect, the energy intensity effect, the economic growth effect, and the population effect [22].

The four indicators are calculated for any year to evaluate the contribution of the above four effects to the change in carbon dioxide emissions. If the calculation yields a positive result, the indicator has increased carbon dioxide emissions. Conversely, if the contribution is negative, the indicator has reduced carbon dioxide emissions. Figure 5 shows the calculation results, showing the contribution of each effect to carbon emissions from 1991 to 2010 [10].

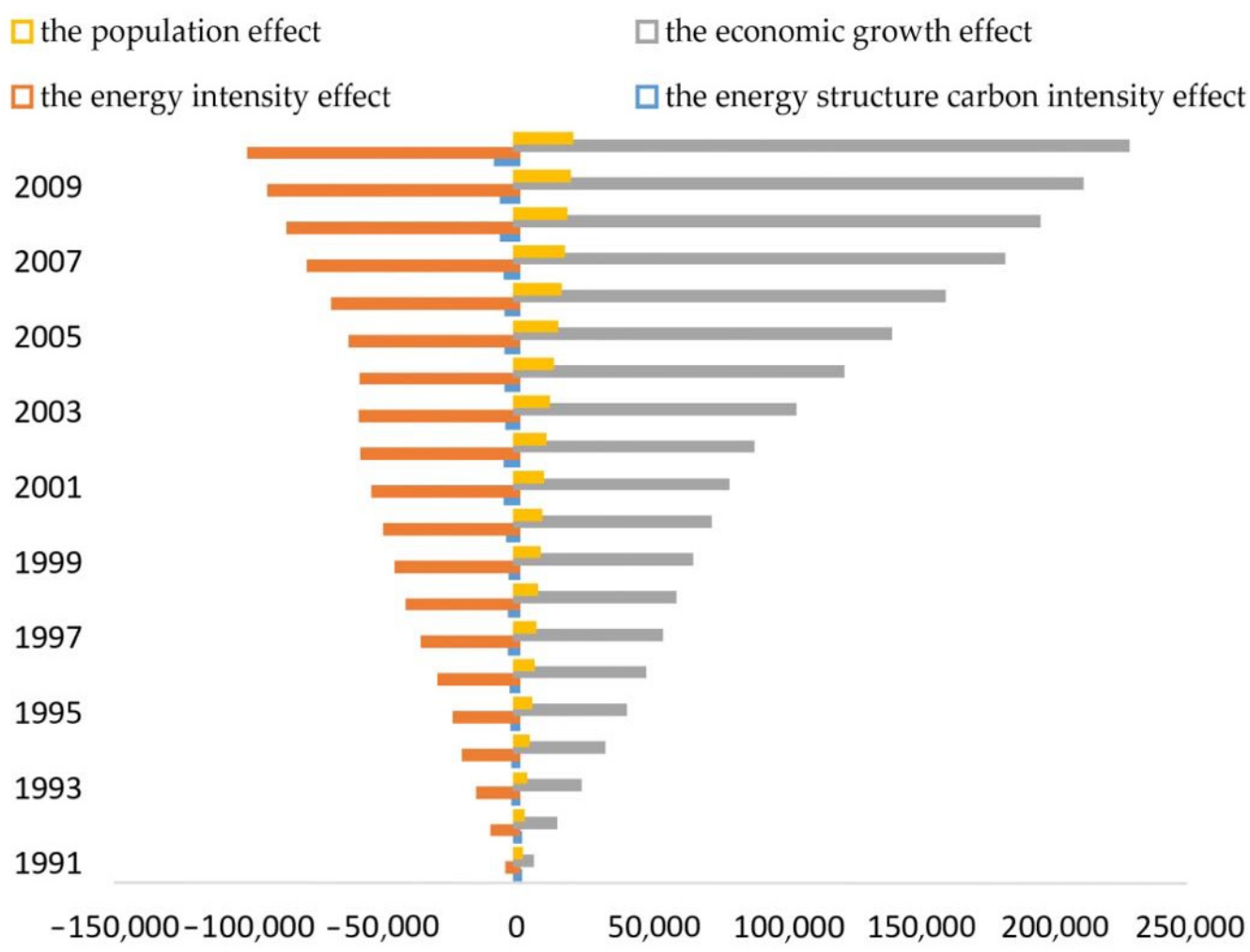

Figure 5. Contribution of each effect to carbon emissions from 1991 to 2010.

It can be seen from the Figure that from 1991 to 2010, with the development of time, the contribution value of each effect increased, especially the economic growth effect and the energy intensity effect.

In addition to the contribution value, the importance of the variables can be judged by calculating the correlation between the factors and carbon emissions. The generalized grey relation analysis was conducted for China's carbon emission data and GDP data from 2001 to 2020 using Equations (2)-(4). The correlation between the two was calculated, and the results were: the absolute correlation was 0.87 , the relative correlation was 0.98 , and the integrated correlation was 0.93 . The grey relation between GDP and carbon emissions was very large; that is, economic growth had a greater impact on carbon emissions.

The combined results of the two evaluation indicators indicate that the economic growth effect and energy intensity effect play a decisive role in carbon emissions. 


\subsection{Supplement to the Decisive Factors-Research on the Problem of Embodied Carbon Transfer}

As the above study was built with formulas and theorems, there will be deviations between the actual process and the theory. To improve the comprehensiveness and timeliness of the study, we investigated and analyzed the impact of carbon emissions.

According to the data released by the International Energy Agency (IEA), the growth of global carbon dioxide emissions before 2000 was mainly caused by developed countries such as the United States, Japan, and those in the European Union. However, since 2000, the emissions of these countries have generally decreased, while the emissions of developing countries such as China and India have increased significantly. There are many reasons for the rapid growth of carbon emissions in developing countries; one that cannot be ignored is the embodied carbon transfer from trade between developed and developing countries [23,24].

The production of any kind of product generates carbon emissions directly or indirectly. The carbon dioxide emitted in the whole production chain to get a certain product is called "embodied carbon". From the perspective of foreign trade, the meaning of "embodied carbon" and "transferred emissions" are basically the same. In the current industrial division of labor, developed countries are at the upper end of the industrial chain, and their export products are mainly high-tech or belong to service industries, with relatively low carbon emissions; in contrast, developing countries' export products are mainly low-end products with high carbon emissions. For a country such as China, which exports low-end products but has a huge trade surplus, the amount of carbon dioxide emissions transferred for other countries through international trade is considerable [25].

Based on the calculation data of embodied carbon emissions from import and export trade from 2002 to 2007, we found that the embodied carbon emissions from the net exports of machinery and equipment manufacturing, metal products manufacturing, and chemical industry always ranked at the top in each sector. The total import and export of these three sectors accounted for $61.41 \%$ of the total import and export in 2007, while the net embodied carbon exports of the three sectors accounted for $69.1 \%$ of China's total net embodied carbon exports. Therefore, reducing the embodied carbon content of exports from these three sectors is of great significance to reduce the embodied carbon emissions of China's import and export trade.

By further study of the relationship between embodied carbon and the structure of export trade sectors from 2002-2010, we found that the sectors with low carbon emissions were: food (1.09), communication (1.42), and textile (1.5) industries. Furthermore, the sectors with high carbon emissions were: metal (6.7), building materials (2), and chemical (4.6) industries. Among them, the chemical sector ranked second after the metal sector in terms of carbon emission share. Similarly, the embodied carbon emissions of high-carbonemission sectors were closely related to their export volume and export volume share, as shown in Figure 6 [10]. Therefore, reducing the embodied carbon in exports of high-carbon sectors by optimizing the trade structure is of great significance to reduce the embodied carbon emissions of China's import and export trade. 


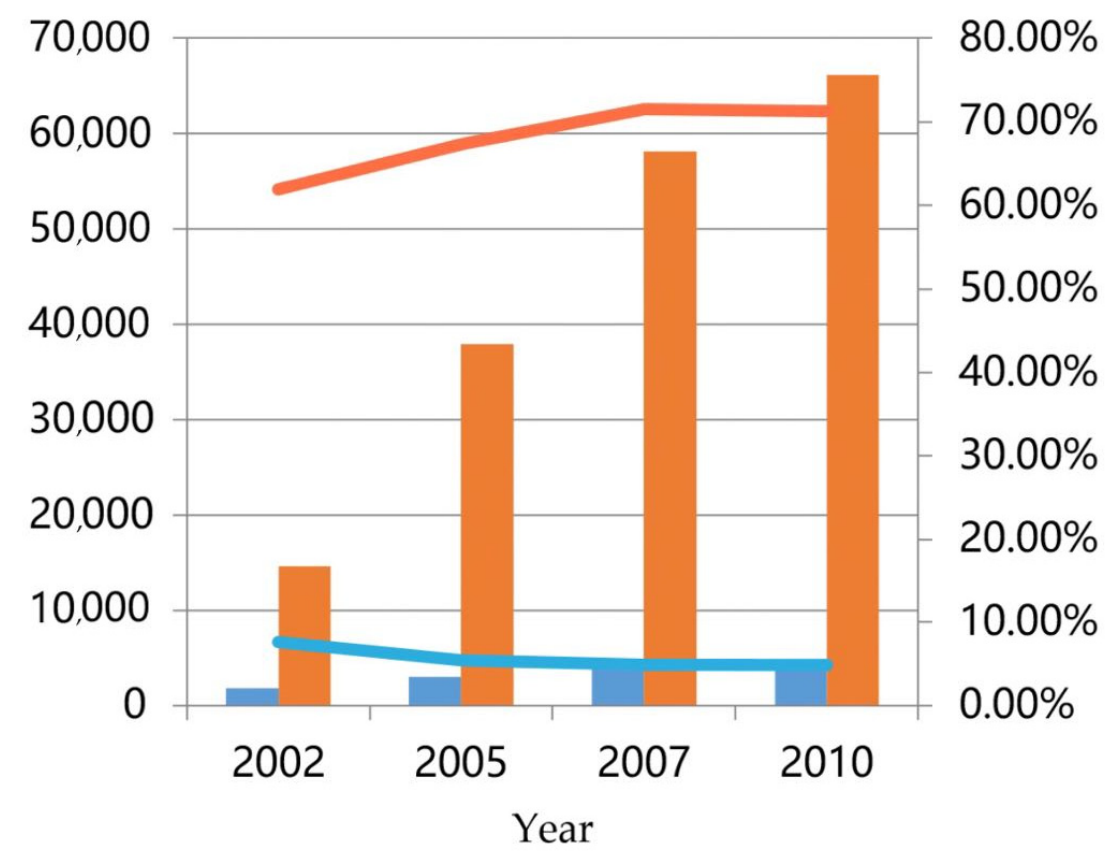

Exports from high-carbon-emission sectors(10000 yuan)

Exports from low-carbon-emission sectors(10000 yuan)

Share of exports from high-carbon-emission sectors

Share of exports from low-carbon-emission sectors

Figure 6. Export volume and export volume share of high-carbon-emission sectors and low-carbonemission sectors.

\subsection{Determination of Influencing Factors for Energy Intensity Effect Based on Best Subsets Regression}

Among the decisive factors affecting carbon emissions, the influencing factors of energy intensity effects need further discussion. In this study, we used the best subsets regression method to analyze it. Energy intensity refers to the energy consumption per unit of GDP, and the specific expression is as follows

$$
I=\frac{E}{G}=\frac{\sum_{i} E_{i}}{\sum_{i} G_{i}}=\sum_{i} \frac{E_{i}}{G_{i}} \times \frac{G_{i}}{\sum_{i} G_{i}}=\sum_{i} I_{i} \times S_{i}
$$

where $I_{i}$ denotes the energy intensity of each industry, and $S_{i}$ denotes the industrial structure of each industry. Therefore, the main influencing factors of energy intensity are the four industrial structures and the corresponding energy intensities. The four industries are primary industry, industry, construction industry, and tertiary industry, and are denoted by $1, \mathrm{~g}, \mathrm{j}$, and 3 , respectively.

From the China Energy Statistical Yearbook 2011 [7], the total energy consumption (E) and GDP $(\mathrm{G})$ of each year, the energy consumption $\left(\mathrm{E}_{\mathrm{i}}\right)$ of each industry, and the GDP $\left(G_{i}\right)$ of each industry were obtained. Then, the energy intensity (I) and its main influencing factors were calculated. Before using the best subsets regression, it is necessary to diagnose the multicollinearity. If there is no multicollinearity, it is not necessary to perform the best subsets regression. The correlation coefficient of the data from 1980 to 2010 was then calculated. The correlation coefficient results of energy intensity and influencing factors are shown in Table 1. 
Table 1. Correlation coefficients of energy intensity and influencing factors.

\begin{tabular}{ccccccccc}
\hline & $\operatorname{lnI}$ & $\ln \mathrm{I}_{1}$ & $\operatorname{lnI_{\mathbf {g}}}$ & $\operatorname{lnI}_{\mathbf{j}}$ & $\operatorname{lnI}_{3}$ & $\operatorname{lnS}_{1}$ & $\operatorname{lnS}_{\mathbf{g}}$ & $\operatorname{lnS}_{\mathbf{j}}$ \\
\hline $\operatorname{lnI}_{1}$ & 0.849 & & & & & & & \\
$\operatorname{lnI}_{\mathrm{g}}$ & 0.991 & 0.806 & & & & & & \\
$\operatorname{lnI}_{\mathrm{j}}$ & 0.922 & 0.878 & 0.894 & & & & & \\
$\operatorname{lnI}_{3}$ & 0.995 & 0.863 & 0.977 & 0.943 & & & & \\
$\operatorname{lnS}_{1}$ & 0.955 & 0.870 & 0.967 & 0.876 & 0.943 & & & \\
$\operatorname{lnS}_{\mathrm{g}}$ & -0.047 & 0.058 & -0.162 & -0.069 & -0.015 & -0.246 & & \\
$\operatorname{lnS}_{\mathrm{g}}$ & -0.842 & -0.878 & -0.820 & -0.913 & -0.852 & -0.842 & 0.128 & \\
$\operatorname{lnS}_{3}$ & -0.979 & -0.869 & -0.951 & -0.900 & -0.986 & -0.921 & -0.096 & 0.789 \\
\hline
\end{tabular}

The results in the table indicate severe multicollinearity among the factors. The best subsets regression was further used to determine the best-fitting model between energy intensity and various factors. The results are shown in Table 2 . The regression equation of energy intensity and each factor is obtained from the above operation as follows

$$
\operatorname{lnI}=0.234+0.618 \ln \mathrm{I}_{\mathrm{g}}+0.270 \operatorname{lnI}_{3}+0.465 \ln S_{\mathrm{g}}
$$

Table 2. Best subsets regression results.

\begin{tabular}{ccccc}
\hline Independent Variable & Coefficient & Standard Error & $\mathbf{T}$ & $p$ \\
\hline Constant & 0.23383 & 0.04562 & 5.13 & 0.000 \\
$\ln \mathrm{I}_{\mathrm{g}}$ & 0.61815 & 0.04049 & 15.27 & 0.000 \\
$\operatorname{lnI}_{3}$ & 0.26957 & 0.02420 & 11.14 & 0.000 \\
$\operatorname{lnS} \mathrm{g}_{\mathrm{g}}$ & 0.46533 & 0.0692 & 6.72 & 0.000 \\
\hline
\end{tabular}

The coefficients of Equation (12), obtained from the fit, indicate that industrial energy intensity and industrial structure play a dominant role in the total energy intensity.

The coefficients of Equation (12), obtained by fitting, show that industrial energy intensity and industrial industry structure play a dominant role in total energy intensity.

\section{Empirical Analysis of the Impact Level of Carbon Emissions}

Next, we developed a VAR model to analyze the long-term equilibrium, integrated effects, dynamic relationship, and impact level of economic growth, energy consumption, foreign trade, and carbon emissions. The data used for the empirical analysis were obtained from the data of carbon emissions (LC), energy consumption (LE), import and export trade (LF), and gross domestic product (LG) from 1981 to 2008 in the China Energy Statistics Yearbook 2011, with a total of 28 samples. As the values of the variables were all large, the data had to be pre-processed, as in Equation (13), before using EViews.

$$
X=\ln (\mathrm{x})
$$

\subsection{ADF Stationarity Test}

Before the empirical analysis, it is necessary to test the stationarity of the data. Only a stationary time series can be used for quantitative analysis, otherwise pseudo-regression will occur. In this study, the ADF unit root test method was used to test the stationarity of four variables: LC, LE, LF, and LG. This method assumes that there is at least one unit root in the tested time series. If the hypothesis is passed, the series is not stationary, and if the reverse is true, the series is stationary. The results are shown in Table 3.

As can be seen from Table 3, the $p$ values of the original time series all exceed 0.05, and the null hypothesis is accepted at the $10 \%$ critical value, so the original data equation is non-stationary. In contrast, the $p$ value of $\Delta \mathrm{LC}$ is 0.0001 , which is far less than 0.05 , rejecting its null hypothesis and showing a stationary state. Therefore, the time series of $\Delta \mathrm{LC}$ is stationary. This shows that the first-order difference series are all stationary series at the $5 \%$ significance level. 
Table 3. Results of the ADF stationarity test for time series.

\begin{tabular}{|c|c|c|c|c|c|c|}
\hline Variable & ADF & $1 \%$ Critical Value & $5 \%$ Critical Value & $10 \%$ Critical Value & $p$ & Conclusion \\
\hline LC & 1.433 & -3.700 & -2.976 & -2.627 & 0.9986 & Non-stationary \\
\hline$\Delta \mathrm{LC}$ & -22.687 & -3.700 & -2.976 & -2.627 & 0.0001 & Stationary \\
\hline$\cdots$ & $\ldots$ & $\ldots$ & $\ldots$ & $\ldots$ & $\ldots$ & $\ldots$ \\
\hline LF & -1.350 & -3.700 & -2.976 & -2.627 & 0.5914 & Non-stationary \\
\hline$\Delta \mathrm{LF}$ & -3.291 & -3.711 & -2.981 & -2.630 & 0.0259 & Stationary \\
\hline
\end{tabular}

\subsection{Construction and Testing of VAR Model}

It is known that the above four variables are all stationary time series, so the original series of these variables can be used to construct multivariate VAR models directly. First, the optimal lag order of the VAR model needs to be determined. Five VAR models with different lag orders were constructed through software, and the results are shown in Table 4.

Table 4. VAR model test results for each lag order.

\begin{tabular}{cccccc}
\hline Lag & LR & FPE & AIC & SC & HQ \\
\hline 0 & NA & $3.52 \times 10^{-9}$ & -8.112216 & -7.915874 & -8.060126 \\
1 & 199.6532 & $3.74 \times 10^{-13}$ & -17.28695 & -16.30524 & -17.02650 \\
2 & 22.25364 & $3.66 \times 10^{-13}$ & -17.43719 & -15.67011 & -16.96838 \\
3 & $32.21775 *$ & $1.07 \times 10^{-13}$ & -19.03274 & -16.48029 & -18.35558 \\
4 & 16.95755 & $8.73 \times 10^{-14} *$ & $-20.12192 *$ & $-16.78410 *$ & $-19.23639 *$ \\
\hline Note: ${ }^{*}$ denotes the optimal lag order determined under this criterion.
\end{tabular}

Note: ${ }^{*}$ denotes the optimal lag order determined under this criterion.

Therefore, the VAR model equation is as follows

$$
\mathrm{Y}_{\mathrm{t}}=\mathrm{A}_{1} \mathrm{Y}_{\mathrm{t}-1}+\mathrm{A}_{2} \mathrm{Y}_{\mathrm{t}-2}+\mathrm{A}_{3} \mathrm{Y}_{\mathrm{t}-3}+\mathrm{A}_{4} \mathrm{Y}_{\mathrm{t}-4}+\mu_{\mathrm{t}}
$$

The stationarity of the VAR model is the premise of empirical analysis. To test whether the VAR model is effective, the AR unit root test was used to test its stationarity, and the test results were obtained through software. As shown in the graph of AR root test results of THE VAR model, the characteristic roots were all in the unit circle, and the mode of all eigenvalues was less than 1, indicating that the VAR model is stationary and satisfies one of the conditions required for the next impulse analysis and variance decomposition.

\subsection{Johanson Cointegration Test}

If there is a linear combination of two or more non-stationary time series that are stationary, these non-stationary (with unit roots) time series are considered to have cointegration relationships with each other, and such a stationary linear combination is called a cointegration equation and can be interpreted as a long-term equilibrium relationship between variables. In this study, Johansen cointegration was used to test the long-term equilibrium relationships among economic growth, energy consumption, foreign trade, and carbon emissions. The results of the test are shown in Table 5.

Table 5. Cointegration test results based on the Johansen methodology.

\begin{tabular}{cccc}
\hline Number of Cointegration Relationships & Trace Statistic & $\mathbf{5 \%}$ Critical Value & $p$ \\
\hline None & 57.714 & 47.856 & 0.0045 \\
At most 1 & 29.424 & 29.797 & 0.0552 \\
At most 2 & 15.459 & 15.495 & 0.0506 \\
\hline
\end{tabular}

It can be seen from the table that under the critical value of 0.05 , the null hypothesis is rejected, and the model has a cointegration vector, which has a cointegration relationship. 
Therefore, we conclude that there is a long-term equilibrium relationship between carbon emissions, energy consumption, economic growth, and foreign trade.

\subsection{Granger Causality Test}

Granger defines causality by A causes B, if by including A in the prediction of B we reduce its variance. The Granger causality test examines "who causes who to change" between variables, that is, the causal relationship between variables. The Granger causality test is often interpreted as whether a variable can be used to improve the predictive ability of other related variables in a VAR model. The test results are shown in Table 6. The null hypotheses tested in the table were all "not a Granger cause". If the probability of the $p$ value was less than 5\%, the null hypothesis was rejected and was a Granger cause. Therefore, we concluded that energy consumption, economic growth, and foreign trade are the unidirectional Granger causes of carbon emissions. Note that $C$ represents carbon emissions, E represents energy consumption, F represents trade volume, and $G$ represents GDP.

Table 6. Granger causality test.

\begin{tabular}{cccc}
\hline Null Hypothesis & F & $p$ & Conclusion \\
\hline E is not a Granger cause of C & 6.510 & 0.006 & Reject \\
C is not a Granger cause of E & 0.423 & 0.660 & Accept \\
F is not a Granger cause of C & 6.443 & 0.006 & Reject \\
C is not a Granger cause of F & 0.928 & 0.410 & Accept \\
G is not a Granger cause of C & 6.669 & 0.005 & Reject \\
C is not a Granger cause of G & 0.621 & 0.547 & Accept \\
\hline
\end{tabular}

\subsection{Impulse Response and Variance Decomposition}

VAR models are unstructured models that do not analyze the individual impact of changes in a single variable on another variable, but rather study the overall impact of changes in the error term on the system. This method is known as the impulse response function analysis method. Impulse response function is used to measure the changes that occur in the whole system when a certain factor in the system changes or fluctuates. After a disturbance term change in a certain period causes a change in the corresponding dependent variable, both the current and later values of other variables change through the dynamics changes of the system. To study the impact of changes in other variables in the VAR model on the variable LC, the impulse response function was established through software. The corresponding figures are shown in Figures 7-9. In the figures, the solid line indicates the impulse response function, and the dashed range indicates the change of the impulse response function within twice the standard deviation.

Figure 7 illustrates that when energy consumption rises, carbon emissions will rise in the long run. Figure 8 shows that carbon emissions will rise in the short term when foreign trade increases. Figure 9 shows that as the economy grows, carbon emissions will fluctuate in the short term.

To compensate for the deficiencies in impulse response analysis and investigate the contribution of other variable changes to the structural impact of the endogenous variable LC, the study further conducted variance decomposition. Variance decomposition is used to explain the extent to which experimental variables are caused by other variables or by themselves, and to further evaluate the importance of different variables by analyzing the contribution of each variable to changes in experimental variables (usually measured by variance). The contribution rate refers to the percentage that a variable contributes to the change of the experimental variable in a certain period. The variance decomposition of the changes of each endogenous variable in the VAR model is shown in Table 7. The results of variance decomposition of carbon emission (C) are shown in Table 8. 


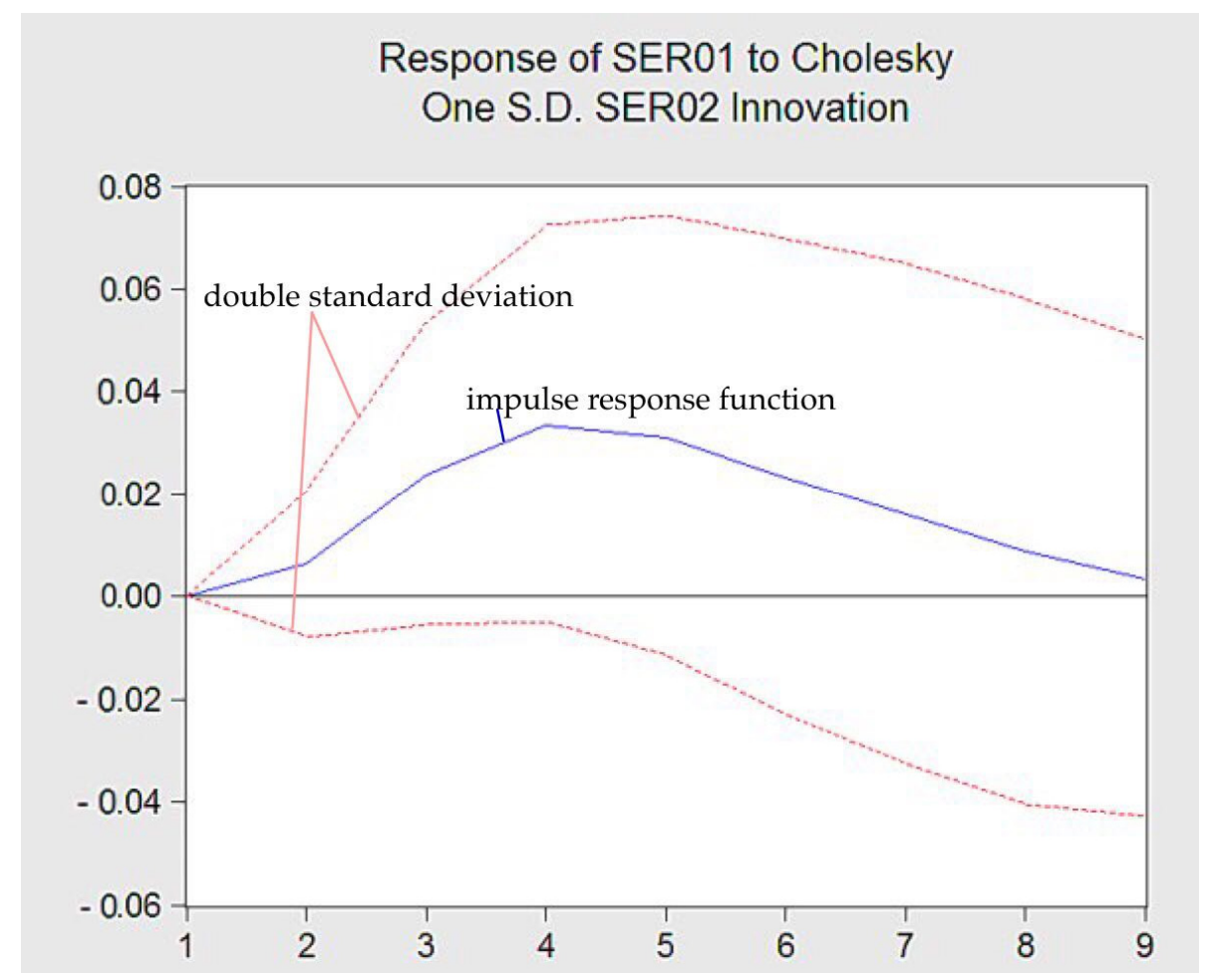

Figure 7. Impulse Response of carbon emissions to energy consumption.

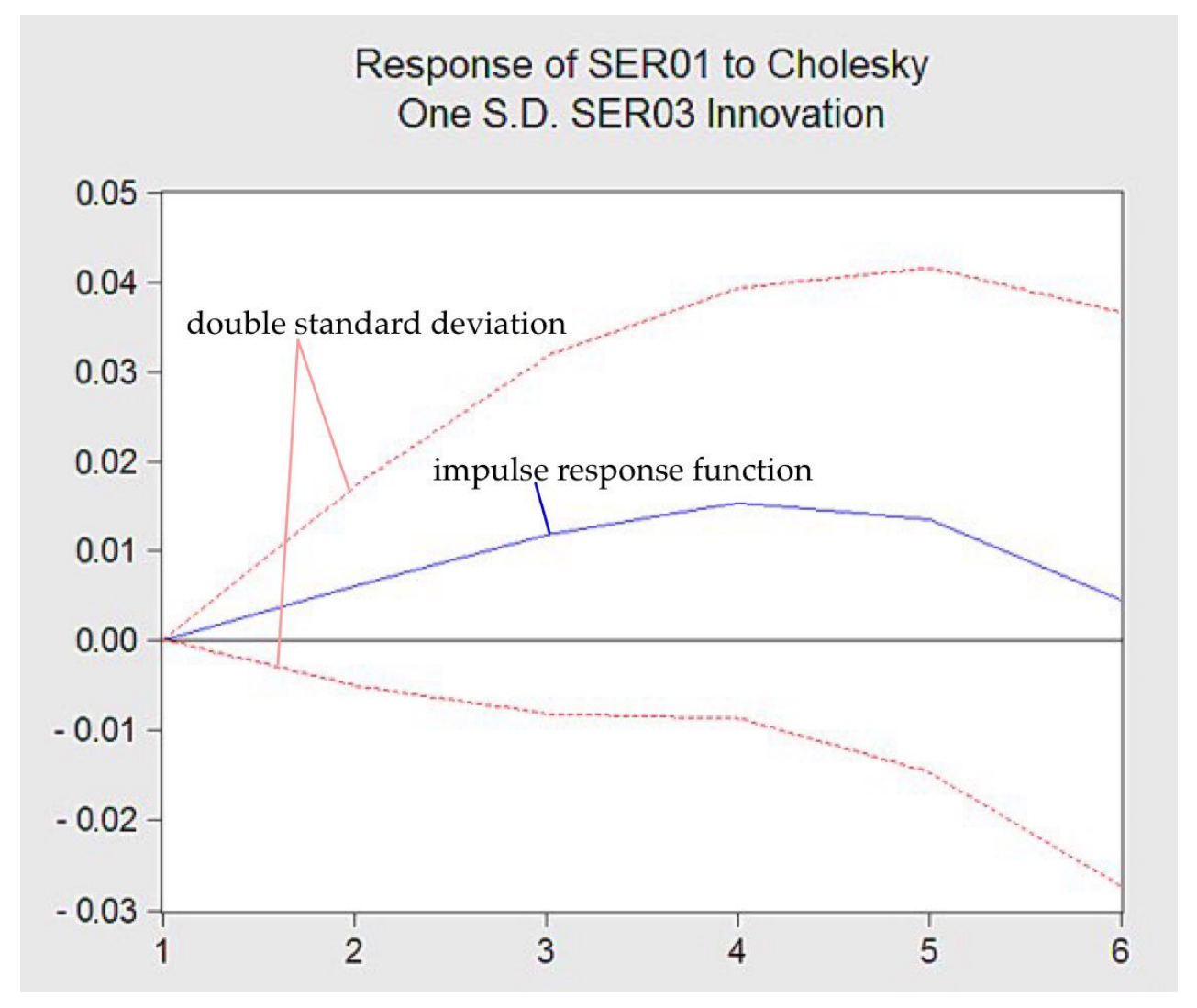

Figure 8. Impulse Response of carbon emissions to foreign trade. 


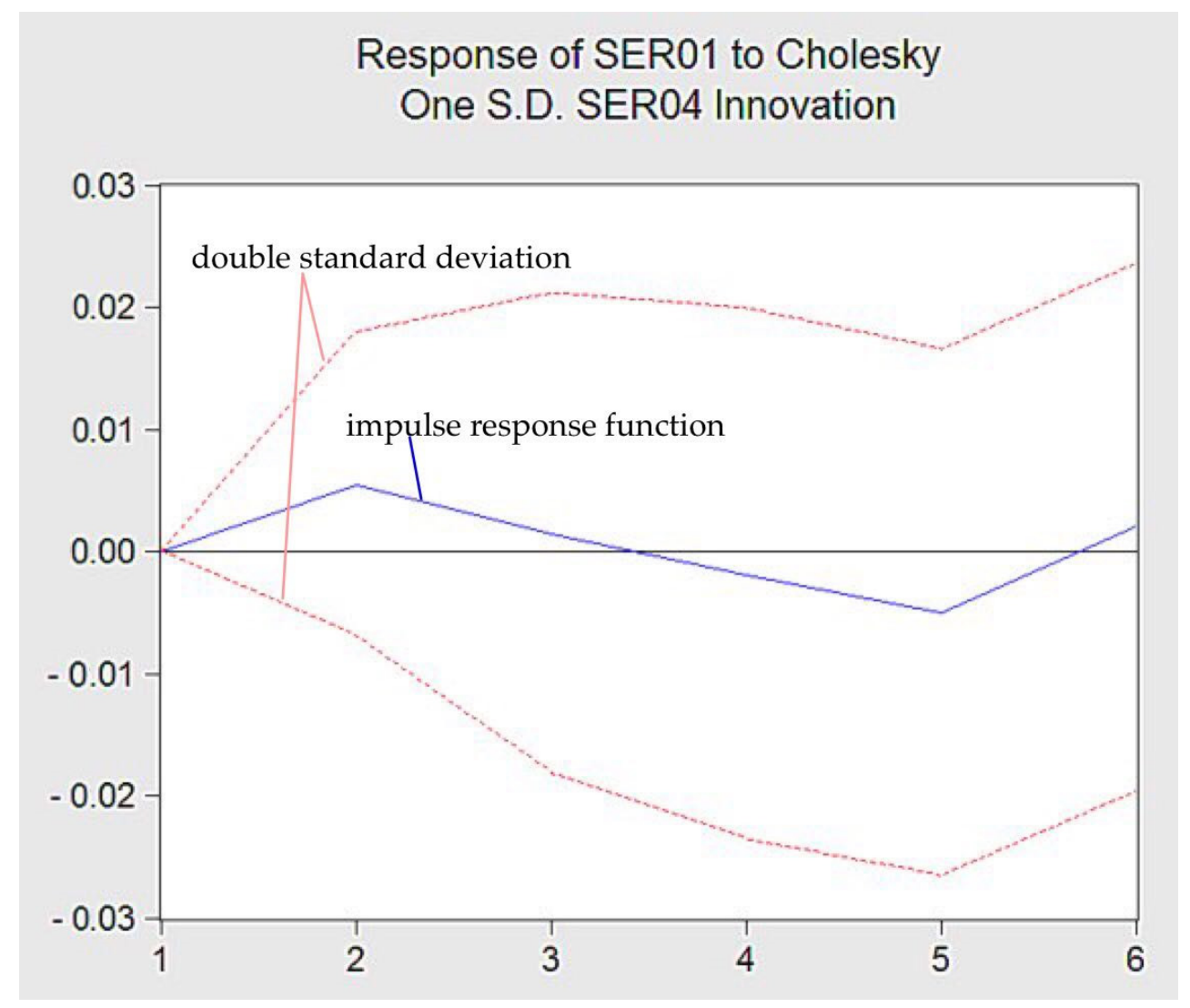

Figure 9. Impulse Response of carbon emissions to economy.

Table 7. The variance decomposition of the changes of each endogenous variable in the VAR model.

\begin{tabular}{|c|c|c|c|c|c|}
\hline \multicolumn{6}{|c|}{ Variance Decomposition of SER01: } \\
\hline Period & S.E. & SER01 & SER02 & SER03 & SER04 \\
\hline 1 & 0.025733 & 100.0000 & 0.000000 & 0.000000 & 0.000000 \\
\hline 2 & 0.056976 & 96.73998 & 1.225831 & 1.112449 & 0.921744 \\
\hline 3 & 0.079187 & 87.04111 & 9.700954 & 2.745691 & 0.512242 \\
\hline 4 & 0.094239 & 75.44090 & 19.58162 & 4.576308 & 0.401167 \\
\hline 5 & 0.104619 & 69.32924 & 24.76672 & 5.346238 & 0.557800 \\
\hline 6 & 0.108300 & 66.55994 & 27.72079 & 5.164244 & 0.555024 \\
\hline 7 & 0.109762 & 65.06747 & 29.14005 & 5.053891 & 0.738591 \\
\hline 8 & 0.111848 & 65.24086 & 28.66245 & 5.220183 & 0.876511 \\
\hline 9 & 0.113692 & 65.55068 & 27.83112 & 5.646488 & 0.971721 \\
\hline 10 & 0.115048 & 65.21887 & 27.48758 & 6.088597 & 1.204949 \\
\hline \multicolumn{6}{|c|}{ Variance Decomposition of SER02: } \\
\hline Period & S.E. & SER01 & SER02 & SER03 & SER04 \\
\hline 1 & 0.020834 & 98.12985 & 1.870154 & 0.000000 & 0.000000 \\
\hline 2 & 0.051500 & 94.74248 & 2.991239 & 1.476769 & 0.789516 \\
\hline 3 & 0.074116 & 85.22627 & 11.43216 & 2.931871 & 0.409702 \\
\hline 4 & 0.089169 & 73.24124 & 21.62727 & 4.828528 & 0.302963 \\
\hline 5 & 0.099671 & 66.52714 & 27.37933 & 5.586158 & 0.507374 \\
\hline 6 & 0.103455 & 63.67268 & 30.46147 & 5.370023 & 0.495831 \\
\hline 7 & 0.104881 & 62.06387 & 32.03155 & 5.242322 & 0.662256 \\
\hline 8 & 0.106766 & 61.98580 & 31.79349 & 5.383107 & 0.837608 \\
\hline 9 & 0.108334 & 62.20047 & 31.13616 & 5.721797 & 0.941576 \\
\hline 10 & 0.109463 & 61.73712 & 31.05388 & 6.056211 & 1.152789 \\
\hline
\end{tabular}


Table 7. Cont.

\begin{tabular}{|c|c|c|c|c|c|}
\hline \multicolumn{6}{|c|}{ Variance Decomposition of SER03: } \\
\hline Period & S.E. & SER01 & SER02 & SER03 & SER04 \\
\hline 1 & 0.131208 & 57.14547 & 20.18304 & 22.67149 & 0.000000 \\
\hline 2 & 0.227305 & 68.57391 & 20.14005 & 10.10791 & 1.178123 \\
\hline 3 & 0.251208 & 67.23248 & 22.51300 & 9.216138 & 1.038378 \\
\hline 4 & 0.274134 & 61.84624 & 27.05847 & 9.566619 & 1528666 \\
\hline 5 & 0.282499 & 59.07566 & 30.44035 & 9.024226 & 1.459772 \\
\hline 6 & 0.284262 & 58.43094 & 31.18387 & 8.919180 & 1.466014 \\
\hline 7 & 0.285619 & 57.97010 & 31.65483 & 8.842031 & 1.533044 \\
\hline 8 & 0.287076 & 57.49799 & 32.15562 & 8.767445 & 1.578948 \\
\hline 9 & 0.289421 & 56.84986 & 32.92185 & 8.642984 & 1.585303 \\
\hline
\end{tabular}

Table 8. The results of variance decomposition of carbon emission (C).

\begin{tabular}{cccc}
\hline Period & E & F & G \\
\hline 1 & 0.000000 & 0.000000 & 0.000000 \\
2 & 1.543961 & 3.082727 & 3.832238 \\
3 & 12.40868 & 2.266033 & 8.119802 \\
4 & 29.31902 & 7.735098 & 9.054170 \\
5 & 40.07627 & 16.41087 & 7.218044 \\
$\ldots$ & $\ldots$ & $\ldots$ & $\ldots$ \\
9 & 44.80328 & 31.73862 & 7.068328 \\
10 & 44.88771 & 31.68107 & 7.019272 \\
\hline
\end{tabular}

Note: E represents energy consumption, F represents trade volume, and G represents GDP.

As can be seen from the table, the contribution of energy consumption to carbon emissions increases with the increase in the period, reaching $44.89 \%$ in the 10 th period. Energy consumption plays an important role, contributing $44.89 \%$ to the predicted variance of carbon emissions, followed by foreign trade, with a contribution of $31 \%$. Economic growth has the smallest contribution rate. The results indicate that China consumes a lot of energy, has a low utilization rate, has an unreasonable structure of import and export commodities, exports a large number of pollution-intensive products, and achieves rapid economic growth at the cost of the environment.

\section{Summary and Recommendations}

Economic development and environmental protection are inseparable.. Based on the results of qualitative analysis, we concluded that the reasons for the increase in carbon emissions in China are high energy consumption, low utilization rate, and an unreasonable structure of import and export commodities. Reducing energy intensity and optimizing energy structure, industrial structure, and trade structure will effectively reduce China's carbon dioxide emissions. In this study, we drew the following conclusions through VAR example verification: (1) According to the established VAR formula, carbon emissions increase by $0.686 \%$, increase by $0.112 \%$, and decrease by $0.031 \%$ when energy consumption, foreign trade, and economic growth increase by $1 \%$, respectively. (2) There is a long-term equilibrium relationship among carbon emissions, energy consumption, and economic growth. Moreover, foreign trade, and energy consumption, economic growth and foreign trade are the unidirectional Granger causes of carbon emissions. (3) Economic growth leads to an increase in carbon emissions in the early stage, but it reduces carbon emissions and improves environmental quality in the later stage. (4) The increase in carbon emissions is mainly due to large energy consumption, a low utilization rate, and an unreasonable structure of import and export commodities in China. (5) Energy consumption, which plays an important role, contributes $44.89 \%$ to the variance of carbon emissions prediction, followed by foreign trade, with a contribution rate of $31 \%$.

Therefore, according to the country's development concept and actual national conditions, the following recommendations are proposed according to the key factors affecting 
carbon emissions: (1) Encourage enterprises to research, develop, and promote energysaving technologies, and stimulate them to promote innovation in energy conversion and utilization through preferential policies. Furthermore, increase investment in advanced energy-saving technologies. (2) Strengthen the incentives and guarantees of laws, regulations, and systems to speed up the improvement in production technologies, achieve industrial upgrading faster and increase unit energy production. (3) Optimize the energy structure, reduce the proportion of coal consumption, vigorously develop clean energy (e.g., hydrogen, wind power, solar energy, and geothermal energy), safely develop nuclear power, and reduce the dependence on fossil energy. (4) Build a hydrogen industry system with a full industrial chain similar to that in the coal industry and the petroleum industry, with green hydrogen as the core. This should cover business processes including hydrogen production, hydrogen storage, hydrogen transportation, hydrogen refueling, hydrogen utilization, hydrogen detection, and hydrogen safety, as well as fields involving hydrogen transportation, hydrogen energy storage, hydrogen chemical industry, and hydrogen metallurgy. (5) Introduce corresponding policies to guide and promote the effective implementation of carbon emission reduction projects. (6) Encourage the development of tertiary industries to reduce greenhouse gas emissions and promote the optimization and transformation of the steel and coal industry to realize low-carbon green industries. (7) Accelerate the optimization of trade structure and reduce the export of embodied carbon in high-carbon sectors.

Author Contributions: Conceptualization, W.F. and J.Y.; methodology, W.F. and Y.D.; software, W.F. and X.L.; validation, Y.D.; formal analysis, W.F.; investigation, W.F.; resources, Y.D.; data curation, X.L.; writing —original draft preparation, W.F.; writing—review and editing, X.L. and Y.D.; visualization, W.F. and X.L.; supervision, J.Y.; project administration, Y.D.; funding acquisition, Y.D. All authors have read and agreed to the published version of the manuscript.

Funding: This work was supported by the National Natural Science Foundation of China (52170112) and Sichuan Province Science and Technology Support Program (2021YFS0301).

Data Availability Statement: Data available on request due to restrictions, e.g., privacy or ethical.

Conflicts of Interest: The authors declare no conflict of interest.

\section{References}

1. Anser, M.K.; Usman, M.; Godil, D.I.; Shabbir, M.S.; Sharif, A.; Tabash, M.I.; Lopez, L.B. Does globalization affect the green economy and environment? The relationship between energy consumption, carbon dioxide emissions, and economic growth. Environ. Sci. Pollut. Res. 2021. [CrossRef]

2. Crippa, M.; Oreggioni, G.; Guizzardi, D.; Muntean, M.; Schaaf, E.; Lo Vullo, E.; Solazzo, E.; Monforti-Ferrario, F.; Olivier, J.G.J.; Vignati, E. Fossil $\mathrm{CO}_{2}$ and GHG Emissions of All World Countries; Publication Office of the European Union: Luxemburg, 2019.

3. Global $\mathrm{CO}_{2}$ Emissions in 2019; International Energy Agency: Paris, France. 2019. Available online: https:/ / www.iea.org/articles / global-CO\$2\$-emissions-in-2019 (accessed on 19 October 2021).

4. United Nations Environment Programme. Emissions Gap Report 2020; United Nations Environment Programme: Nairobi, Kenya, 2020. Available online: https:/ / www.unep.org/emissions-gap-report-2020 (accessed on 19 October 2021).

5. Yang, T.; Dong, Q.; Du, Q.; Du, M.; Dong, R.; Chen, M. Carbon dioxide emissions and Chinese OFDI: From the perspective of carbon neutrality targets and environmental management of home country. J. Environ. Manag. 2021, 295, 113120. [CrossRef] [PubMed]

6. Lin, B.; Sun, C. Evaluating carbon dioxide emissions in international trade of China. Energy Policy 2010, 38, 613-621. [CrossRef]

7. Energy Statistics Department of National Bureau of Stabletatistics. China Energy Statistical Yearbook; China Statistics Press: Beijing, China, 2021. Available online: https://navi.cnki.net/knavi/yearbooks/YCXME/detail (accessed on 19 October 2021).

8. Oreggioni, G.D.; Ferraio, F.M.; Crippaa, M.; Muntean, M.; Schaaf, E.; Guizzardi, D.; Solazzo, E.; Duerr, M.; Perry, M.; Vignatia, E. Climate change in a changing world: Socio-economic and technological transitions, regulatory frameworks and trends on global greenhouse gas emissions from EDGAR v.5.0. Glob. Environ. Chang. 2021, 70, 102350. [CrossRef]

9. National Bureau of Statistics. Statistical Bulletin of the People's Republic of China on National Economic and Social Development in 2020. 2021. Available online: http:/ / www.stats.gov.cn/tjsj/zxfb/202102/t20210227_1814154.html (accessed on 19 October 2021).

10. National Bureau of Statistics. China Statistical Yearbook; China Statistics Press: Beijing, China, 2021. Available online: https: //navi.cnki.net/knavi/yearbooks/YINFN/detail (accessed on 19 October 2021). 
11. Chunyu, L.; Zain-ul-Abidin, S.; Majeed, W.; Raza, S.M.F.; Ahmad, I. The non-linear relationship between carbon dioxide emissions, financial development and energy consumption in developing European and Central Asian economies. Environ. Sci. Pollut. Res. 2021, 1-16. [CrossRef] [PubMed]

12. Wen, W.; Feng, C.; Zhou, H.; Zhang, L.; Wu, X.; Qi, J.; Yang, X.; Liang, Y. Critical provincial transmission sectors for carbon dioxide emissions in China. Renew. Sustain. Energy Rev. 2021, 149, 111415. [CrossRef]

13. Chen, J.; Cui, H.; Xu, Y.; Ge, Q. Long-term temperature and sea-level rise stabilization before and beyond 2100: Estimating the additional climate mitigation contribution from China's recent 2060 carbon neutrality pledge. Environ. Res. Lett. 2021, 16, 074032. [CrossRef]

14. Ma, T.; Wang, Y. Globalization and environment: Effects of international trade on emission intensity reduction of pollutants causing global and local concerns. J. Environ. Manag. 2021, 297, 113249. [CrossRef] [PubMed]

15. Abban, O.J.; Hongxing, Y. What initiates carbon dioxide emissions along the Belt and Road Initiative? An insight from a dynamic heterogeneous panel data analysis based on incarnated carbon panel. Environ. Sci. Pollut. Res. 2021, 1-20. [CrossRef] [PubMed]

16. Zhang, C.; Zhang, W.; Luo, W.; Gao, X.; Zhang, B. Analysis of Influencing Factors of Carbon Emissions in China's Logistics Industry: A GDIM-Based Indicator Decomposition. Energies 2021, 14, 5742. [CrossRef]

17. Liu, Y.; Li, L.; Song, Y. Regional Differences in Influencing Factors of Carbon Emissions in China's Logistics Industry. Resour. Dev. Mark. 2017, 33, 1439-1443.

18. Zhang, Y.; Tang, Z. Driving factors of carbon embodied in China's provincial exports. Energy Econ. 2015, 51, 445-454. [CrossRef]

19. Sun, L.; Cui, H.; Ge, Q. Driving Factors and Future Prediction of Carbon Emissions in the 'Belt and Road Initiative' Countries. Energies 2021, 14, 5455. [CrossRef]

20. Piłatowska, M.; Geise, A.; Włodarczyk, A. The Effect of Renewable and Nuclear Energy Consumption on Decoupling Economic Growth from $\mathrm{CO}_{2}$ Emissions in Spain. Energies 2020, 13, 2124. [CrossRef]

21. Piłatowska, M.; Geise, A. Impact of Clean Energy on $\mathrm{CO}_{2}$ Emissions and Economic Growth within the Phases of Renewables Diffusion in Selected European Countries. Energies 2021, 14, 812. [CrossRef]

22. Mai, L.; Ran, Q.; Wu, H. A LMDI decomposition analysis of carbon dioxide emissions from the electric power sector in Northwest China. Nat. Resour. Modeling 2020, 33, e12284. [CrossRef]

23. Li, H.; Tang, Z.P. A comparative analysis of trade embodied carbon emissions of developed and developing countries from the perspective of value-added trade. J. Cent. South Univ. For. Technol. Soc. Sci. 2021, 15, 20-30. (In Chinese) [CrossRef]

24. Kanemoto, K.; Moran, D.; Lenzen, M.; Geschke, A. International trade undermines national emission reduction targets: New evidence from air pollution. Glob. Environ. Chang. 2014, 24, 52-59. [CrossRef]

25. Qi, Y.; Li, H.M.; Xu, M. Accounting embodied carbon in import and export in China. China Popul. Resour. Environ. 2008, 18, 8-13. (In Chinese) 